\title{
$\$$ Research Square

\section{A Research on Stress-Induced Deformation of Thin Copper Substrate in Double-Sided Lapping}

Jiang Guo

Dalian University of Technology https://orcid.org/0000-0002-9523-7881

\section{Zeng-Xu He}

Dalian University of Technology

\section{Bin Wang}

Dalian University of Technology

\section{Bo Pan}

Dalian University of Technology

\section{Qian Bai}

Dalian University of Technology

Jin-Xing Kong

China Academy of Engineering Physics

Ren-Ke Kang ( $\sim$ kangrk@dlut.edu.cn )

Dalian University of Technology

\section{Original Article}

Keywords: machining deformation, double-sided lapping, residual stress, finite element simulation

Posted Date: January 15th, 2021

DOl: https://doi.org/10.21203/rs.3.rs-141382/v1

License: (c) (1) This work is licensed under a Creative Commons Attribution 4.0 International License.

Read Full License 


\section{Abstract}

Double-sided lapping is an ultra-precision machining method capable of obtaining high-precision surface. However, during the lapping process of thin pure copper substrate, the workpiece will be warped due to the influence of residual stress-related, including the processing stress and initial residual stress, which will deteriorate the flatness of the workpiece and ultimately affect the performance of components. In this study, finite element method (FEM) was adopted to study the effect of residual stress-related on the deformation of pure copper substrate during double-sided lapping. Considering the initial residual stress of the workpiece, the stress caused by the lapping and their distribution characteristics, a prediction model was proposed for simulating workpiece machining deformation in lapping process by measuring the material removal rate of the upper and lower surfaces of the workpiece under the corresponding parameters. The results showed that the primary cause of the warping deformation of the workpiece in the double-sided lapping is the redistribution of initial residual stress caused by uneven removal of double-sided material. The finite element simulation results were in good agreement with the experimental results.

\section{Introduction}

High-precision pure copper substrates and wafers are indispensable materials for precision physical experiments and ultra-large-scale integration (ULSI) because of their excellent electrical conductivity and other physical properties [1-2]. As a difficult-to-cut material, there are many problems in using traditional processing methods. Therefore, double-sided lapping has gradually become one of the key processing methods in precision machining due to its high removal rate, good flatness, high parallelism and low stress introduction [3]. However, since the pure copper thin substrate is sensitive to stress, warping deformation may occur during the processing, resulting in deterioration of workpiece flatness.

Some research showed that the factors causing workpiece deformation are related to the existence of initial residual stress and the introduction of machining stress [4-5]. For the processing deformation caused by stress, the most researches at present are mainly focused on turning and milling processes. Huang et al. studied the influence of initial residual stress and machining stress on the deformation of the monolithic component. And the finite element model was established to predict the machining deformation. It is concluded that the deformation caused by the machining stress accounts for about $10 \%$ of the total deformation of the part, and the deformation caused by the initial residual stress of the blank accounts for about 90\% [6]. Gao et al. established a numerical analysis model which only considered the deformation caused by the initial residual stress of the workpiece. The model was validated by finite element simulation and experiment [7]. By verifying the influence of different processing strategies on the deformation, it was concluded that symmetrical or semi-symmetrical processing was beneficial to reduce the deformation [8]. Masoudi et al. studied the effects of machining force, temperature, stress distribution, and work piece thickness on deformation in turning thin-walled workpiece made of Al7075-T6 alloy [9]. Young et al. obtained the relationship between tool parameters and machining residual stress when milling 7050-T7451 aluminum alloy and the influence of relevant 
influencing factors on machining deformation [10]. Nervi et al. conducted experimental research on aluminum alloys. It's concluded that when the thickness of the workpiece is smaller, the degree of processing deformation is positively related to the processing residual stress [11]. Cerutti et al. considered the influence of fixture, processing sequence and other factors in the processing of aeronautical parts and established the finite element prediction model of processing deformation, which provided the basis for optimizing the process [12-13]. For the study of the acquisition method of machining stress, Zhang et al. proposed a new method for predicting deformation caused by surface processing stress in finite element models. Compared with the mapping method, the new method based on equivalent force method takes less computer resources and greatly improves computational efficiency [14]. However, few studies have been reported on the prediction of machining deformation in lapping.

This paper introduces a novel deformation prediction approach in double-sided lapping using finite element model. The effects of initial residual stress, machining stress and their distribution characteristics on the deformation of thin copper substrate during lapping are considered respectively. The initial data used in the finite element model of deformation prediction were obtained through experiments. The double-sided lapping process was simulated by the element birth and death method and the mapping method to predict the deformation of workpiece. The simulation results showed that the primary cause of the warping deformation of the workpiece in the double-sided lapping is the redistribution of initial residual stress caused by uneven removal of double-sided material. The prediction approach is verified by a double-sided lapping experiment.

\section{Methodology}

For thin copper substrate, the deformation is sensitive to stress during the double-sided lapping process. In order to predict the deformation of the workpiece, the finite element method is used to study the effects of initial residual stress and machining stress [15]. The procedure of deformation analysis in doublesided lapping is as shown in Figure 1. Firstly, the initial data used in the simulation including initial residual stress, machining stress and material removal rate need to be acquired by experiments. Then, the finite element method is used to simulate the deformation of the workpiece considering the effects of initial residual stress and the residual stress, respectively. For initial residual stress, the redistribution of residual stress after double-sided lapping will lead to deformation of the workpiece. To study the effect of initial residual stress, the state of initial residual stress of workpiece needs to be introduced into the finite element model. In the finite element model, the workpiece is divided into several layers along the thickness direction. The average values of the measured initial residual stresses along different thicknesses are introduced into the corresponding layers. The material removal process was simulated using element birth and death method based on the material removal rate in the double-sided lapping. Considering the simulation time and accuracy, the mesh in the processing area is refined, while the mesh in the non-processing area is sparse. The influence of material removal on the workpiece deformation is illustrated by non-equal surface material removal. After the material is removed, the deformation of the workpiece caused by redistribution of initial residual stress can be obtained by finite element analysis. For machining stress, it usually exists on the surface of workpiece after double-sided lapping, which is 
difficult to obtain directly. Therefore, this paper uses the mapping method to obtain the processing stress required in the finite element model indirectly. In the method, the thicker workpiece is machined by the same process, and the deformation after the process is ignored due to the strong rigidity of the workpiece. Then, the residual stress is evaluated in the surface, and it can be considered as the machining stress of the process. In order to study the effect of machining stress on workpiece deformation, only the machining stress on the surface of workpiece obtained through the above methods is introduced into the finite element model.

The effect of uniformity of processing stress on the same surface is considered by introducing processing stress through sub-regions. The deformation of the workpiece caused by machining stress can be obtained through finite element analysis. Finally, the double-sided lapping experiment was used to verify the accuracy of the proposed prediction approach for workpiece deformation.

\section{Data Acquisition}

\subsection{Initial residual stress}

To predict the effect of initial residual stress on workpiece deformation, the initial residual stress state of the workpiece needs to be obtained and introduced into the finite element software as an initial condition. The acquisition process of thin copper sample for double-sided lapping including rolling, annealing, turning, annealing, in which the two annealing treatments are to reduce the residual stress. In order to obtain the initial residual stress of the workpiece, the stripping method combined with the electronic speckle pattern interferometry hole-drilling method (PRISM by Stresstech Oy, Vaajakoski, Finland) was used to measure the original residual stress [16-17]. To get the average stress on the whole surface, randomly select 10 positions on the workpiece for peeling. Because the workpiece is made by rolling and turning methods symmetrically, the residual stress distributes symmetrically along the $Z$ direction. The measuring principle and method are as shown in Figure 2. Initial residual stress distribution along the $X$ and $\mathrm{Y}$ direction of the workpiece is presented in Figure 3.

\subsection{Machining stress}

Similar to the initial residual stress, the acquisition of machining stress is a prerequisite for finite element simulation. During the machining process, external factors such as force and temperature will lead to additional machining stress [19-20]. Generally, there are two ways to obtain processing stress. 1) Through the finite element simulation of the machining process, the machining stress state is obtained. For milling and turning, the finite element simulation of the machining process is easy. However, due to the random distribution of the shape and position of the abrasive particles during grinding process, the double-sided lapping process is complicated, which is difficult to establish a finite element simulation. 2) Obtain the machining stress state through experiments. However, it is difficult to measure the machining stress directly due to the machining stress release in low-rigidity workpiece after double-sided lapping process. Therefore, the mapping method has been proposed and gradually applied to the study of machining deformation. Residual stress results of simple and thicker workpiece can be obtained by experiment or 
simulation, which can be mapped to more complex actual workpiece to derive the effect of machining stress on the actual workpiece [21-22]. Therefore, this paper chose pure copper component with $\Phi 200 \times 7$ $\mathrm{mm}$ which had been subjected to multiple heat treatments to reduce the initial residual stress, mapped the residual stress results of the workpiece to the workpiece with $3.2 \mathrm{~mm}$ thickness, to obtain the influence of the machining stress on the deformation under the relevant processing parameters.

Double-sided lapping was carried out on the double-sided lapping machine (YJ-6B5LA \& YJ-6B5LC by Yujing Machinery Co., Ltd., Hunan, China) shown in Figure 4. The experimental parameters are shown in Table 1.

Table 1 Experiment conditions

\begin{tabular}{|llllll|}
\hline Machine & $\begin{array}{l}\text { Pressure } \\
(\mathrm{psi})\end{array}$ & $\begin{array}{l}\text { Upper plate Rotation } \\
\text { speed (rpm) }\end{array}$ & $\begin{array}{l}\text { Lower plate Rotation } \\
\text { speed (rpm) }\end{array}$ & Slurry & $\begin{array}{l}\text { Processing } \\
\text { time (min) }\end{array}$ \\
\hline $\begin{array}{l}\text { Double-sided } \\
\text { lapping }\end{array}$ & 1.5 & 40 & 40 & Water & 30 \\
\hline
\end{tabular}

Because the stress was uniformly distributed in the surface and the depth of the stress layer is small (about $20 \mu \mathrm{m}$ ) [3], the residual stress of the machined surface is measured by XRD ( $\mu$-X360s by Pulstec, Japan). The position of measurement and results are shown in Figure 5.

\subsection{Double-sided removal rate}

In order to simulate the actual machining process, it is necessary to obtain the material removal rate of the upper and lower surfaces of the workpiece. In the process of double-sided lapping, the removal rate of workpiece is related to the processing parameters, and the removal rate of upper and lower surfaces of workpiece is also different, so it is necessary to measure the removal rate of double-sided lapping under the corresponding parameters [23-24]. As the removal amount is small, the confocal microscope is used for measurement. The difference before and after lapping is the material removal values of corresponding parameters, as shown in Figure 6. The measurement positions and results are shown in Figure7. As can be seen from Figure 7 (b), the material removal rate on the upper and lower surfaces is close to 2:1 under the experimental conditions in Table 1.

\section{Simulation Results}

\subsection{Effect of initial residual stress}

In order to investigate the effect of initial residual stress on machining deformation, a finite element simulation was performed using commercial software ABAQUS. In the simulation, the workpiece model is a thin copper sheet of $\emptyset 200 \times 3.2 \mathrm{~mm}$, and its mechanical properties are shown in Table 2 . The initial residual stresses in Figure 3 are introduced into the workpiece model using a predefined field. Considering 
the processing time, based on material removal rate of 2: 1 between the upper and lower surfaces, the removal simulation was performed on the workpiece using element birth and death method to process the workpiece to $3.05 \mathrm{~mm}$. To make the model easier, the model is based on several assumptions: (1) the initial residual stresses are uniformly distributed in each layer of the surface. (2) the workpiece surface is an ideal flat. (3) the material removal on the same surface is uniform. (4) the machining stress introduction is ignored during the material removal.

Table 2 The main mechanical properties of the thin copper sheet

\begin{tabular}{|ll|}
\hline Parameters & Value \\
\hline Young's modulus & $119000 \mathrm{Mpa}$ \\
\hline Poisson' s ratio & 0.34 \\
\hline Density & $8960 \mathrm{~kg} / \mathrm{m} 3$ \\
\hline
\end{tabular}

The element type of the mesh set in the FEM is C3D8R, with a total of 112896 elements and 119136 nodes. In order to ensure that the workpiece can be deformed freely without rigid movement, the five nodes at the center of the workpiece are set as fixed constraints. After the material is removed, the initial residual stress is redistributed, and the deformation simulation results are shown in Figure 8.

In order to study the influence of material removal on the deformation of workpiece, the above finite element model was simulated by equal removal of upper and lower surface materials. The workpiece was processed to $3.15 \mathrm{~mm}$ by the method of element birth and death according to the material removal rate of 1:1 on upper and lower surface. The deformation simulation results are shown in Figure 9.

Figure 8 is a deformation diagram of the machining process after considering only the influence of the initial residual stress with uneven material removal of upper and lower surfaces. It can be seen that the workpiece undergoes symmetrical warping deformation, and the maximum deformation of the workpiece occurs at the edge of the workpiece, and the maximum deformation is $20.96 \mu \mathrm{m}$. It can be seen from Figure 9 that the maximum deformation of the workpiece is only $5 \mu \mathrm{m}$ with the uniformly material remove of the upper and lower surface. Because the material is removed uniformly, the residual stress can be released uniformly which has little effect on the deformation of the workpiece. However, due to the uneven removal of the upper and lower surface materials during double-sided lapping, the redistribution of initial residual stress results in warpage of the workpiece.

\subsection{Effect of machining stress}

In view of the influence of processing stress on deformation, there are two mapping strategies. Strategy 1 is to introduce the average of the residual stresses on the upper and lower surfaces as measured in Figure 5 into the finite element model. Strategy II is to consider the uneven distribution of the residual stress on the workpiece surface caused by the uneven distribution of the workpiece pressure and the 
abrasive trajectory during the lapping process, the two factors have different effects on the radial direction of the workpiece [25], which makes the distribution of the residual stress show a certain trend along the radius direction. According to the above analysis and measurement results in Figure 5, the finite element simulation was carried out by adding stress in three zones on the upper and lower surfaces of the finite element model with thickness of $3.15 \mathrm{~mm}$ as shown in Figure 10. The simulation result is shown in Figure 11.

Only considering the deformation of the workpiece with the corresponding thickness caused by the machining stress, the finite element simulation results are shown in Figure 11. It can be seen that the warpage degree of the simulation results using strategy II is greater than that of strategy I. However, due to the approximation of the stress induced by double-sided lapping on both sides of the workpiece under this parameter, the deformation is very small, which is only 0.268 um and can be neglected.

From the results listed above, it is obvious that the deformation caused by initial residual stress is much larger than the machining stress. Thus, the deformation after double-sided lapping is mainly caused by the initial residual stress.

\section{Experiment Verification}

In order to verify the accuracy of the proposed finite element model for predicting deformation, $\varnothing 200 \times 3.2$ $\mathrm{mm}$ workpieces were selected, and a double-sided lapping machine was used for the double-sided lapping process deformation test. Using the experimental parameters in Table 1, the workpieces thickness was machined to $3.15 \mathrm{~mm}$, and the deformation of the workpiece was measured by a coordinate measuring instrument. Since the three-coordinate measuring machine cannot measure the position at the extreme edge, the measuring position is the diameter of the largest deformation, and the measuring length is $190 \mathrm{~mm}$. The actual measurement results and simulation results are shown in Figure 12. The maximum simulated deformation value and the measured value are compared in Table 3.

Using the experimental parameters in Table 4 for a double-sided lapping experiment, the material removal rates on the upper and lower surfaces of the workpiece are almost the same, as shown in Figure 13. The measurement results are shown in Figure 14 that the maximum deformation of the workpiece is $10.6 \mu \mathrm{m}$.

It can be seen from the above that in the process of double-sided lapping, because of the existence of the initial residual stress of the workpiece, the stress redistribution of the workpiece in the process of uneven material removal will eventually lead to warping deformation of the workpiece. However, because of the machining stress under this processing parameter, the two-sided introduction of the workpiece is almost the same. Although warping deformation will also occur, the value is small and can be neglected. The experimental results are in good agreement with the simulation results, and the error is nearly $29.39 \%$, which is within acceptable range. There are three possible reasons explaining the error. 1) Limited by measuring instruments, the measurement of residual stress existence error. In addition, there is a gap between the residual stress distribution obtained by the fitting method and the actual workpiece. 2) The workpiece model in the finite element adopts an ideal plane, but the initial sample after heat treatment 
will be deformed. 3) Due to the influence of pressure and relative velocity of the workpiece and the abrasives, the material removal at the center and edges of the workpiece surface is uneven, which affected the actual machining deformation.

Table 4 Experiment conditions

\begin{tabular}{|llllll|}
\hline Machine & $\begin{array}{l}\text { Pressure } \\
(\mathrm{psi})\end{array}$ & $\begin{array}{l}\text { Upper plate Rotation } \\
\text { speed (rpm) }\end{array}$ & $\begin{array}{l}\text { Lower plate Rotation } \\
\text { speed (rpm) }\end{array}$ & Slurry & $\begin{array}{l}\text { Processing } \\
\text { time (min) }\end{array}$ \\
\hline $\begin{array}{l}\text { Double-sided } \\
\text { lapping }\end{array}$ & 1.5 & 20 & 40 & Water & 30 \\
\hline
\end{tabular}

\section{Conclusions}

In this paper, a finite element simulation model for predicting the deformation of double-sided lapping is created. The initial residual stress, processing stress and their distribution characteristics are considered. The effects of these two factors on the processing deformation were studied. The results reveal that the root cause of the warping deformation of the workpiece in the double-side lapping is the redistribution of initial residual stress, which is caused by uneven removal of double-sided material. The main conclusions are as follows:

(1) The mechanism of machining deformation of parts was studied. Because of the existence of the initial residual stress of the workpiece and the introduction of the machining stress, the stress redistribution of the workpiece in the process of uneven material removal will eventually lead to warping deformation of the workpiece.

(2) The effects of initial residual stress and machining stress on workpiece deformation were studied. Under the experimental parameters, the initial residual stress plays a major role in the deformation of the workpiece, and the machining stress has little effect on the deformation of the workpiece due to the similarity introduced by the double-sided.

(3) Under the experimental parameters, the maximum warpage of the workpiece is $27.12 \mu \mathrm{m}$, which is compared with the simulation results, which proves the accuracy of the simulation mode.

Future work will focus on coupling effects of uneven material removal in-plane, initial residual stress and machining residual stress to optimize the prediction model on the deformation of workpiece.

\section{Declaration}

\section{Funding}

Supported by National Key Research and Development Program (Grant No. 2018YFA0702900). Science Challenge Project (Grant No. TZ2016006), National Natural Science Foundation of China (Grant No. 51975096). 
Availability of data and materials

The datasets supporting the conclusions of this article are included within the article.

\section{Authors' contributions}

The author' contributions are as follows: Jiang Guo and Ren-Ke Kang was in charge of the whole trial; Zeng-Xu He wrote the manuscript; Bin Wang, Bo Pan, Qian Bai and Jin-Xing Kong assisted with sampling and laboratory analyses.

\section{Competing interests}

The authors declare no competing financial interests.

\section{Consent for publication}

Not applicable

\section{Ethics approval and consent to participate}

Not applicable

\section{References}

1. D P Tracy, D B Knorr. Texture and microstructure of thin copper films. CJournal of electronic materials, 1993, 22(6): 611-616

2. B Wang, $\mathrm{H} R$ Zhang, $\mathrm{Y} H$ Zhang, et al. Effect of $\mathrm{Cu}$ substrate roughness on growth of graphene domains at atmospheric pressure. Materials Letters, 2014, 131: 138-140

3. B Pan, R K Kang, J Guo, et al. Precision Fabrication of Thin Copper Substrate by Double-sided Lapping and Chemical Mechanical Polishing. Journal of Manufacturing Processes, 2019, 44: 47-54

4. S Gao, Z Dong, R Kang, et al. Warping of silicon wafers subjected to back-grinding process. Precision Engineering, 2015, 40: 87-93

5. Z Wang, J Sun, L Liu, et al. An analytical model to predict the machining deformation of frame parts caused by residual stress. Journal of Materials Processing Technology, 2019, 274:116282

6. X Huang, J Sun, J Li. Finite element simulation and experimental investigation on the residual stressrelated monolithic component deformation. The International Journal of Advanced Manufacturing Technology, 2015, 77(5-8): 1035-1041

7. H Gao, Y Zhang, Q Wu, et al. An analytical model for predicting the machining deformation of a plate blank considers biaxial initial residual stresses. The International Journal of Advanced Manufacturing Technology, 2017, 93(1-4): 1473-1486

8. C Zhan, W Yang. A high efficient surface-based method for predicting part distortions in machining and shot peening. International Journal of Mechanical Sciences, 2016, 119: 125-143 
9. S Masoudi, S Amini, E Saeidi, et al. Effect of machining-induced residual stress on the distortion of thin-walled parts. The International Journal of Advanced Manufacturing Technology, 2015, 76(1-4): 597-608

10. K A Young. Machining-induced residual stress and distortion of thin parts. Dissertation for the Doctoral. Saint Louis: Washington University, 2005

11. S Nervi, B A Szabo, K A Young. Prediction of distortion of airframe components made from aluminum plates. AIAA Journal, 2009, 47(7): 1635-1641

12. $X$ Cerutti, $K$ Mocellin. Parallel finite element tool to predict distortion induced by initial residual stresses during machining of aeronautical parts. International Journal of Material Forming, 2015,8(2):255-268

13. X Cerutti, S Arsene, K Mocellin. Prediction of machining quality due to the initial residual stress redistribution of aerospace structural parts made of low-density aluminium alloy rolled plates. Journal of Material Forming, 2016,9(5):677-690

14. S Zhang. Research on ultra-precision processing of pure copper sheet with large diameter-thickness ratio. Zhejiang University of Technology, 2019 (in Chinese)

15. S Y Yang, J H Kim. Computation of Stress Field During Additive Manufacturing by Explicit Finite Element Method. Journal of Korean Powder Metallurgy Institute, 2020, 27(4):318-324

16. Q Wu, N P Xue, Y D Zhang, et al. A prediction model of the extrusion deformation with residual stress on 6063 aluminum alloy aeronautical plate considering different extrusion parameters. International Journal of Advanced Manufacturing Technology, 2020, 107(3-4):1-11

17. J Guo, H Fu, B Pan, et al. Recent Progress of Residual Stress Measurement Methods: A Review. Chinese Journal of Aeronautics, 2019

18. Q Bai, H Feng, L K Si, et al. A Novel Stress Relaxation Modeling for Predicting the Change of Residual Stress During Annealing Heat Treatment. Metallurgical and Materials Transactions A, 2019, 50(12): 5750-5759

19. C Sun, S Xiu, Y Hong, et al. Prediction on residual stress with mechanical-thermal and transformation coupled in DGH. International Journal of Mechanical Sciences, 2020: 105629

20. Z C Lin, W L Lai, H Y Lin, et al. The study of ultra-precision machining and residual stress for NiP alloy with different cutting speeds and depth of cut. Journal of Materials Processing Tech, 2000, 97(1-3):200-210.

21. S M Afazov, A A Becker, T H Hyde. Mathematical modeling and implementation of residual stress mapping from microscale to macroscale finite element models. Journal of manufacturing science and engineering, 2012, 134(2)

22. S M Ratchev, S M Afazov, A A Becker, et al. Mathematical modelling and integration of micro-scale residual stresses into axisymmetric FE models of Ti6Al4V alloy in turning. CIRP Journal of Manufacturing Science and Technology, 2011, 4(1): 80-89

23. Y Hashimoto, $T$ Sano, T Furumoto, et al. Development an identification method of friction coefficient between wafer and carrier in double-sided lapping. Precision Engineering, 2019. 
24. B J Cho, H M Kim, R Manivannan, et al. On the mechanism of material removal by fixed abrasive lapping of various glass substrates. Wear, 2013, 302(1-2):1334-1339.

25. T Kasai. Akinematic analysis of disk motion in a double sided polisher for chemical mechanical planarization (CMP). Tribology International, 2008, 41(2): 111-118

\section{Tables}

Due to technical limitations, table 3 is only available as a download in the Supplemental Files section.

\section{Figures}

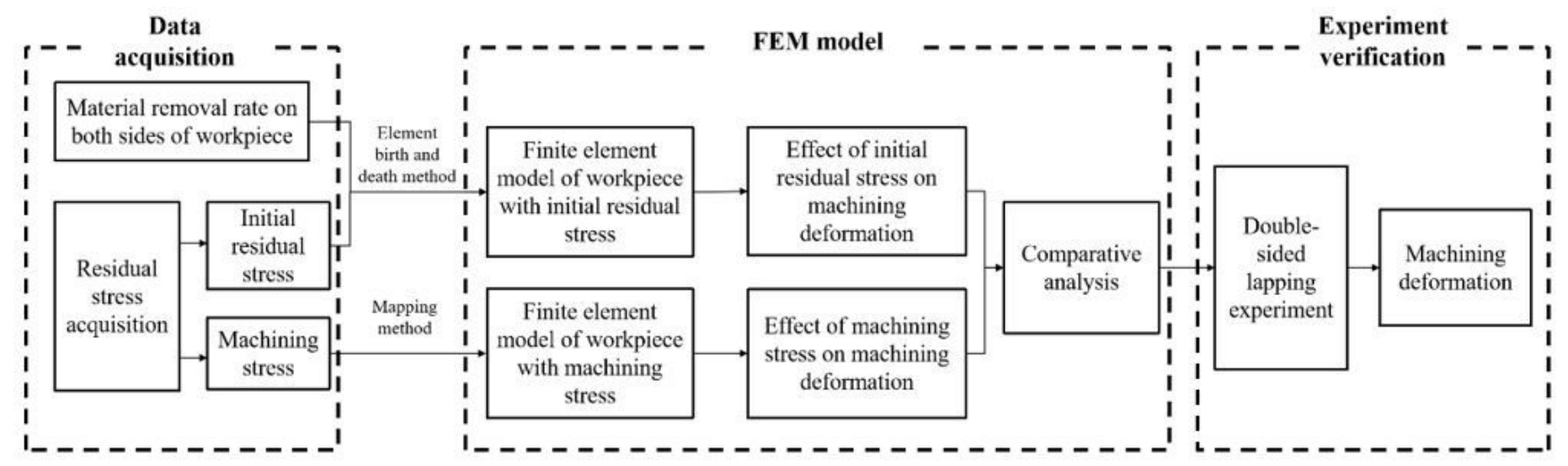

\section{Figure 1}

Schematic illustration of procedure of deformation analysis in double-sided lapping 
(a)

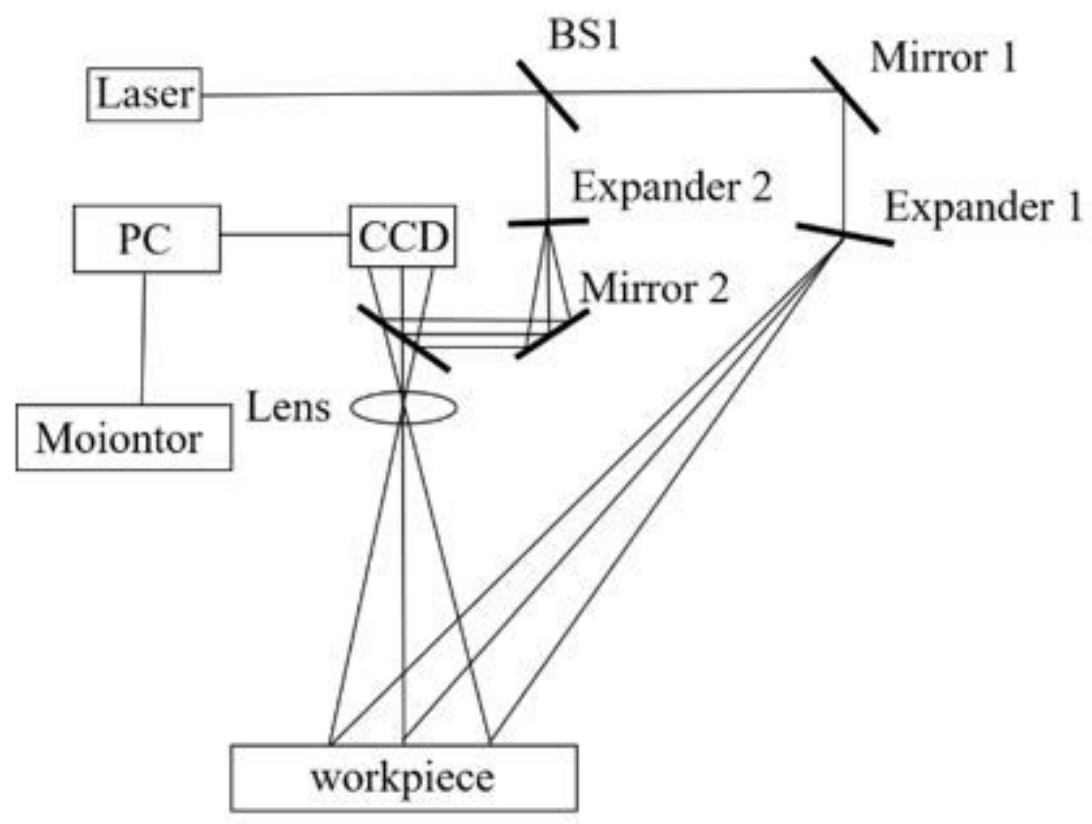

(b)

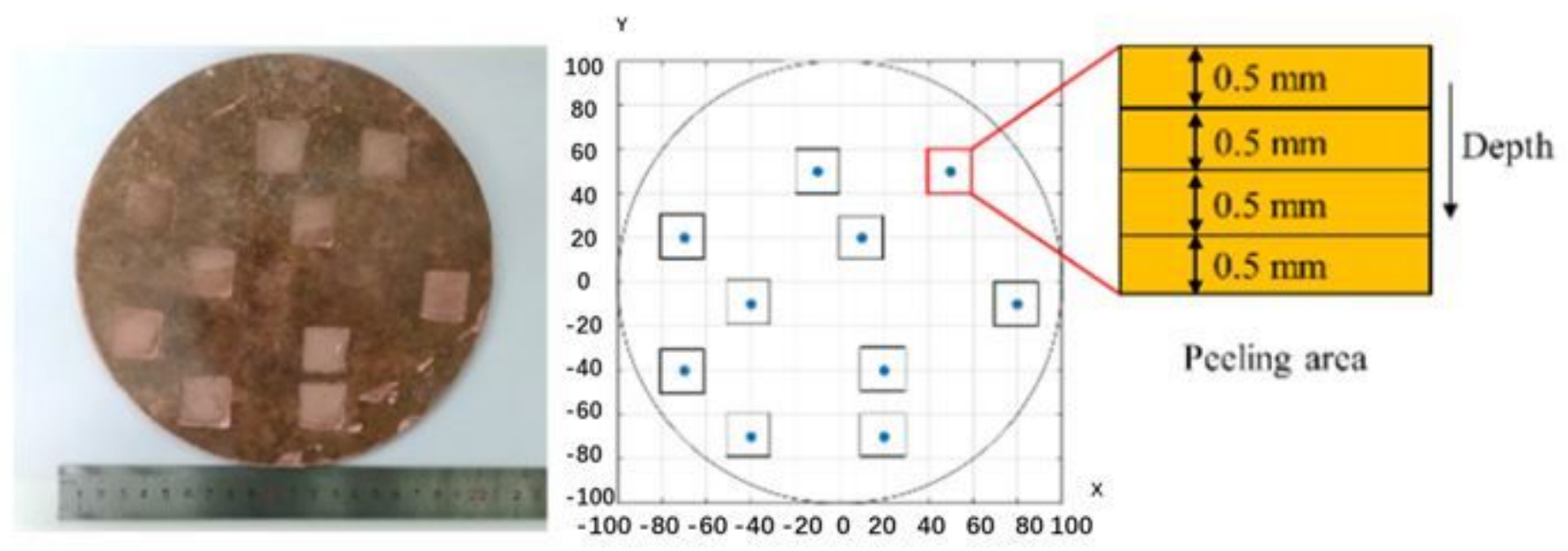

Figure 2

Initial residual stress measurement (a) measuring principle of PRISM [18] and (b) method 
(a)

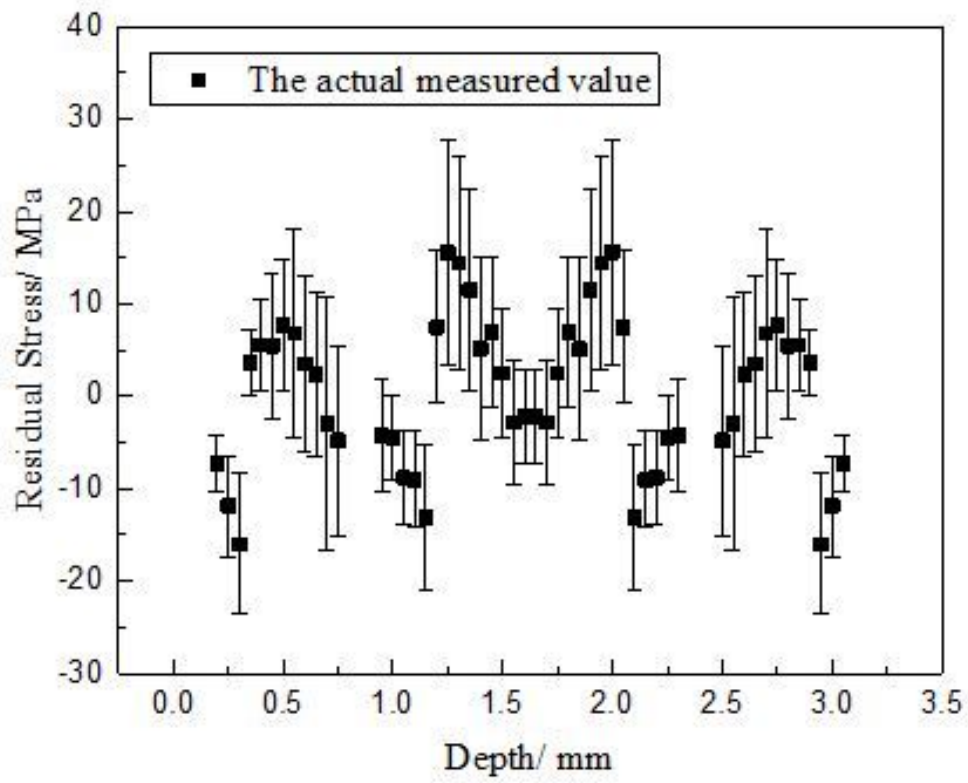

(b)

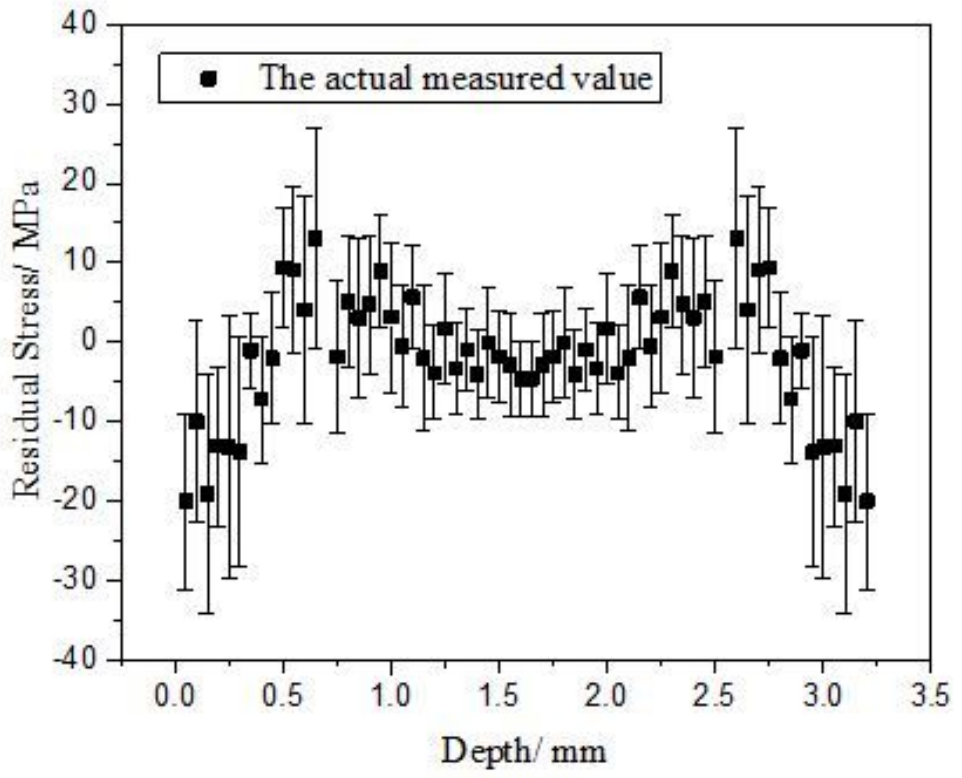

Figure 3

Initial residual stress thickness direction distribution in pure copper thin substrate: (a) Y direction; (b) $\mathrm{X}$ direction 


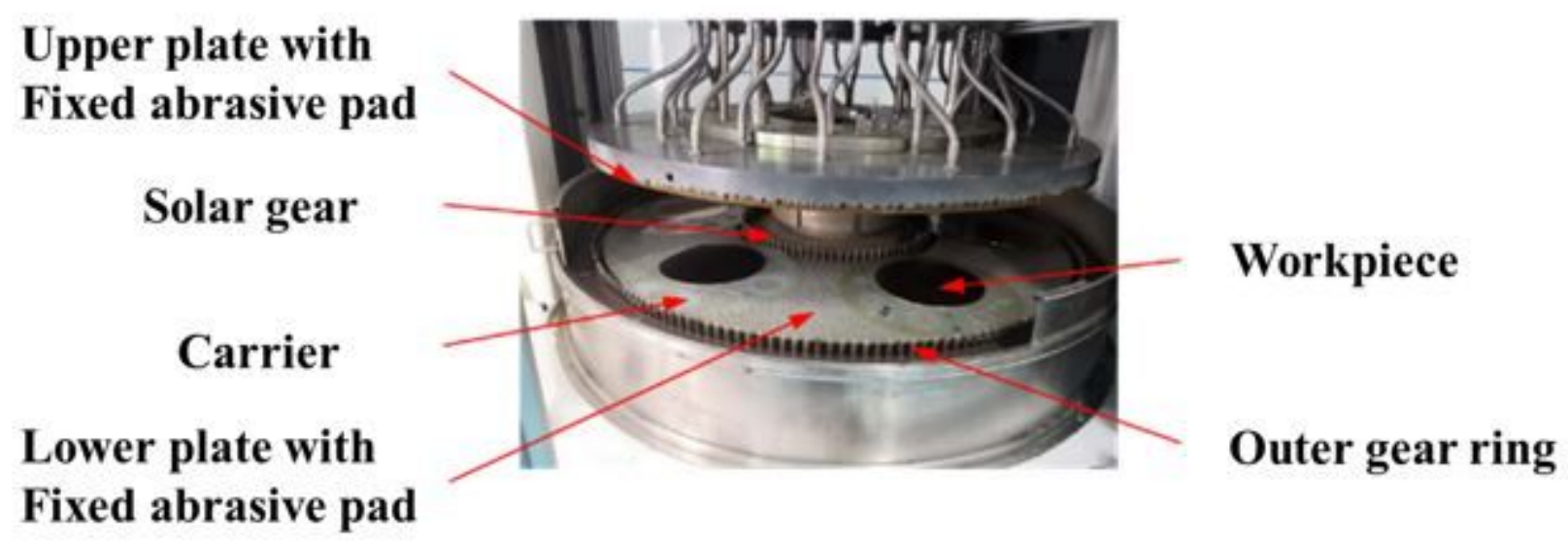

Figure 4

Experiment setups 
(a)

(b)
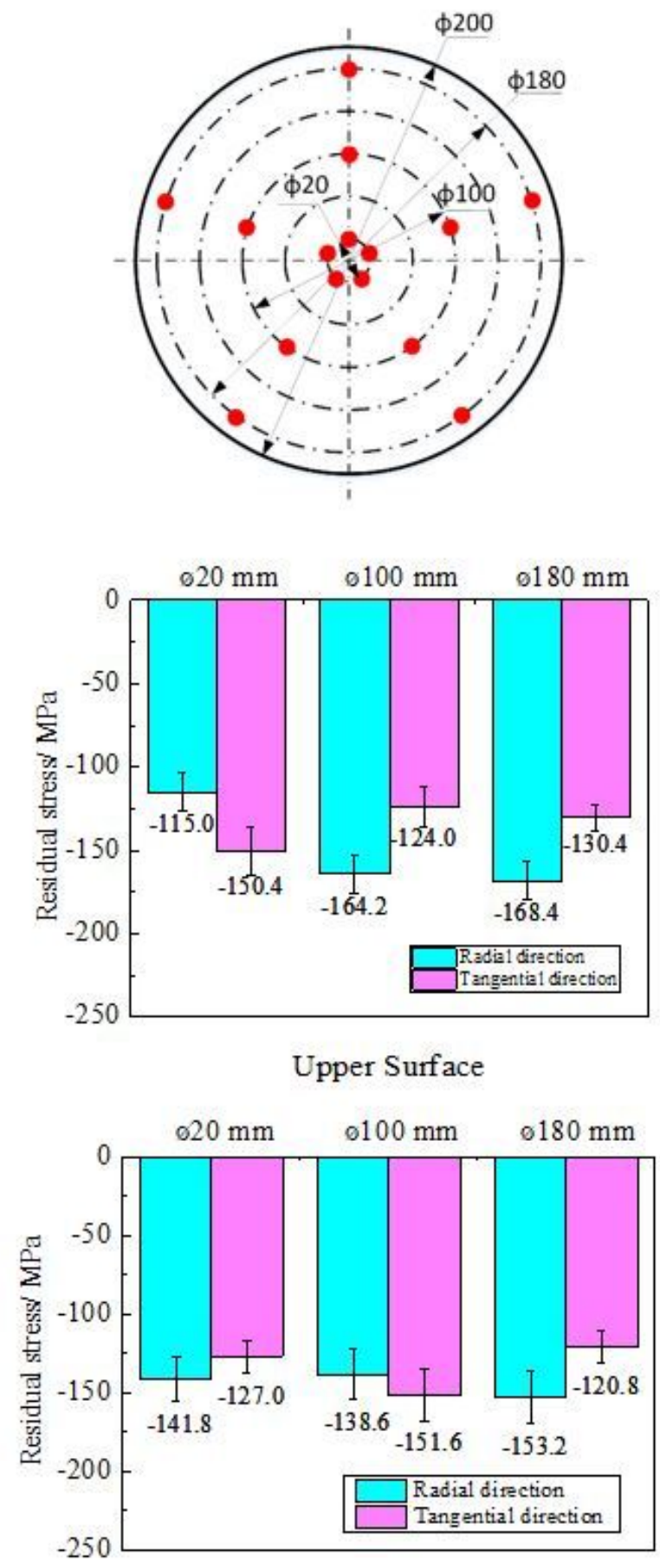

Lower surface

\section{Figure 5}

Residual stress of the machined surface (a) the position of measurement and (b) results 


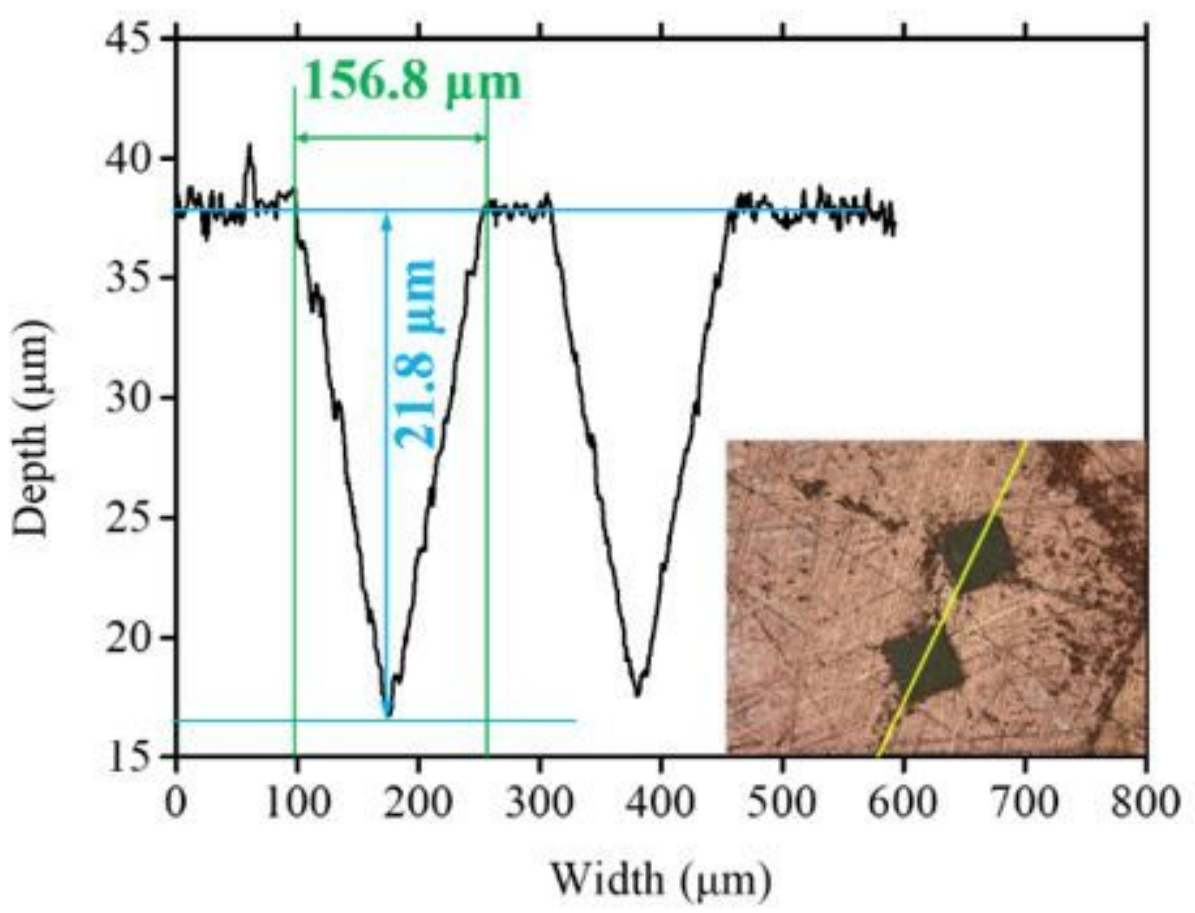

Figure 6

Indentation shape measurements 
(a)

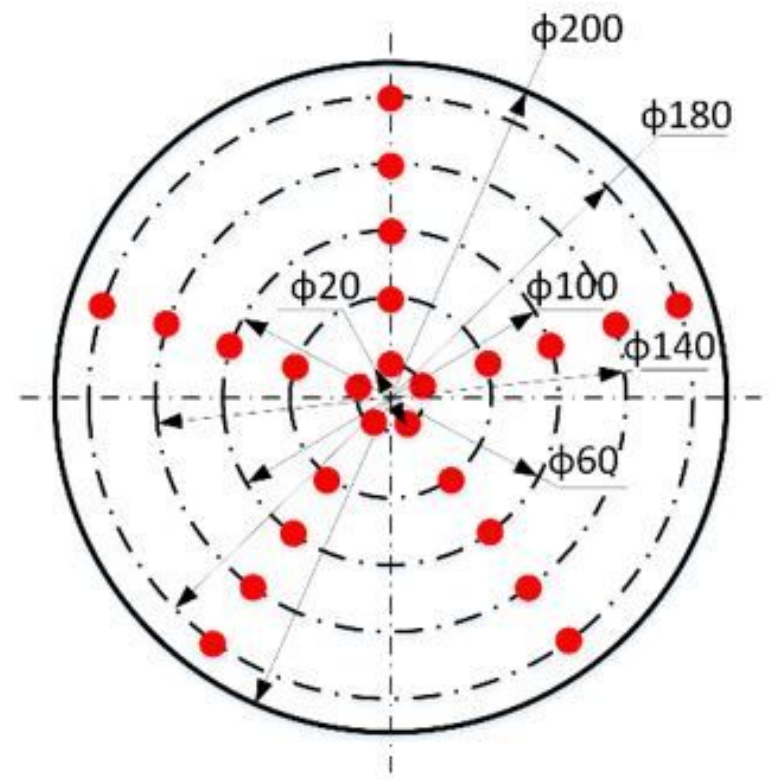

(b)

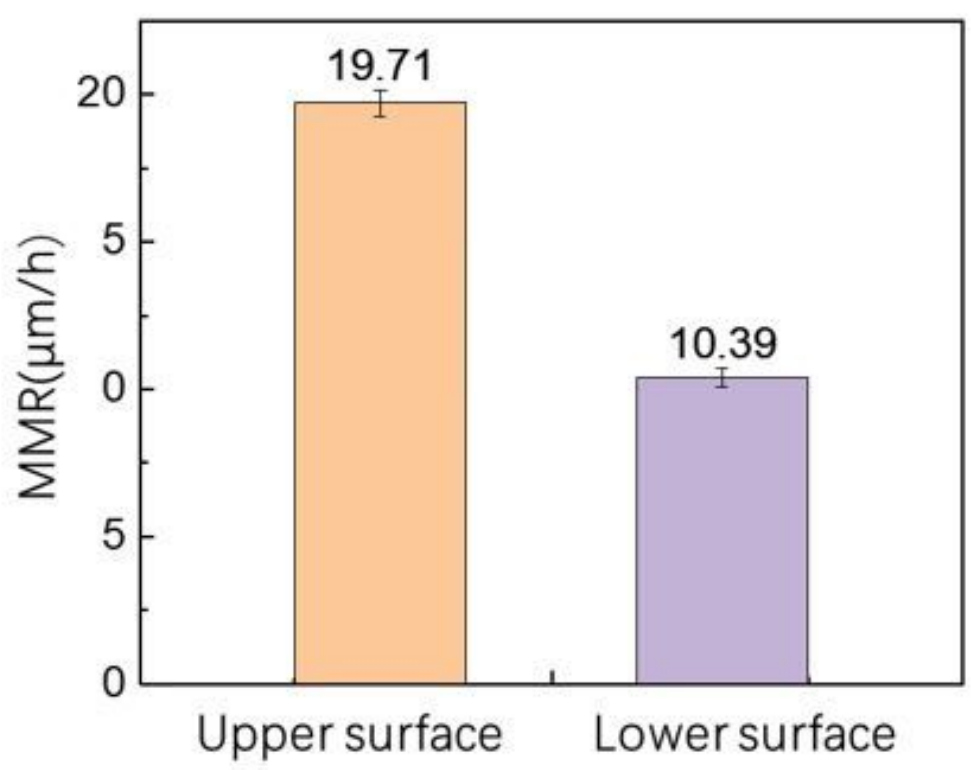

Figure 7

Material removal rate (a) measuring positions and (b) results 


\section{Measure position}

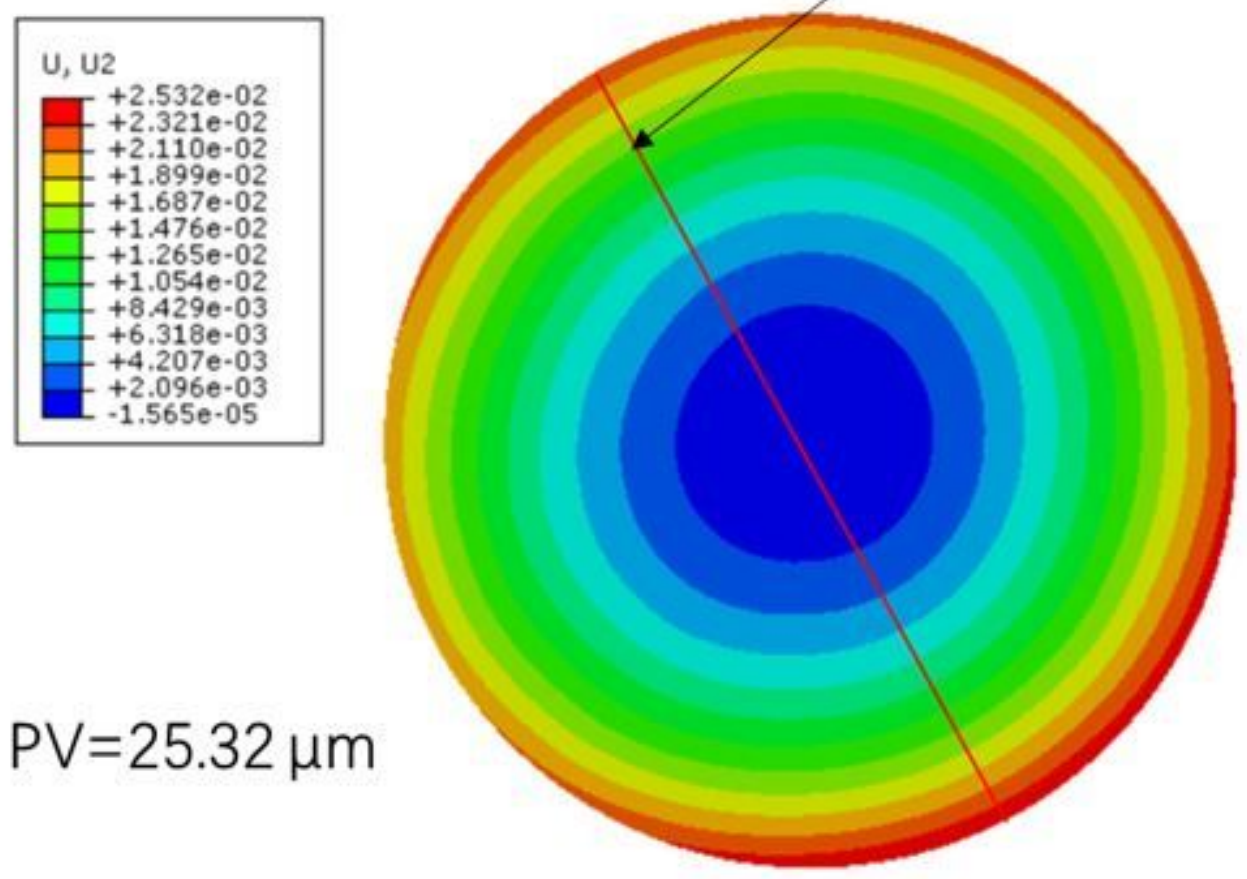

Figure 8

Deformation finite element simulation result with uneven material removal of upper and lower surfaces 

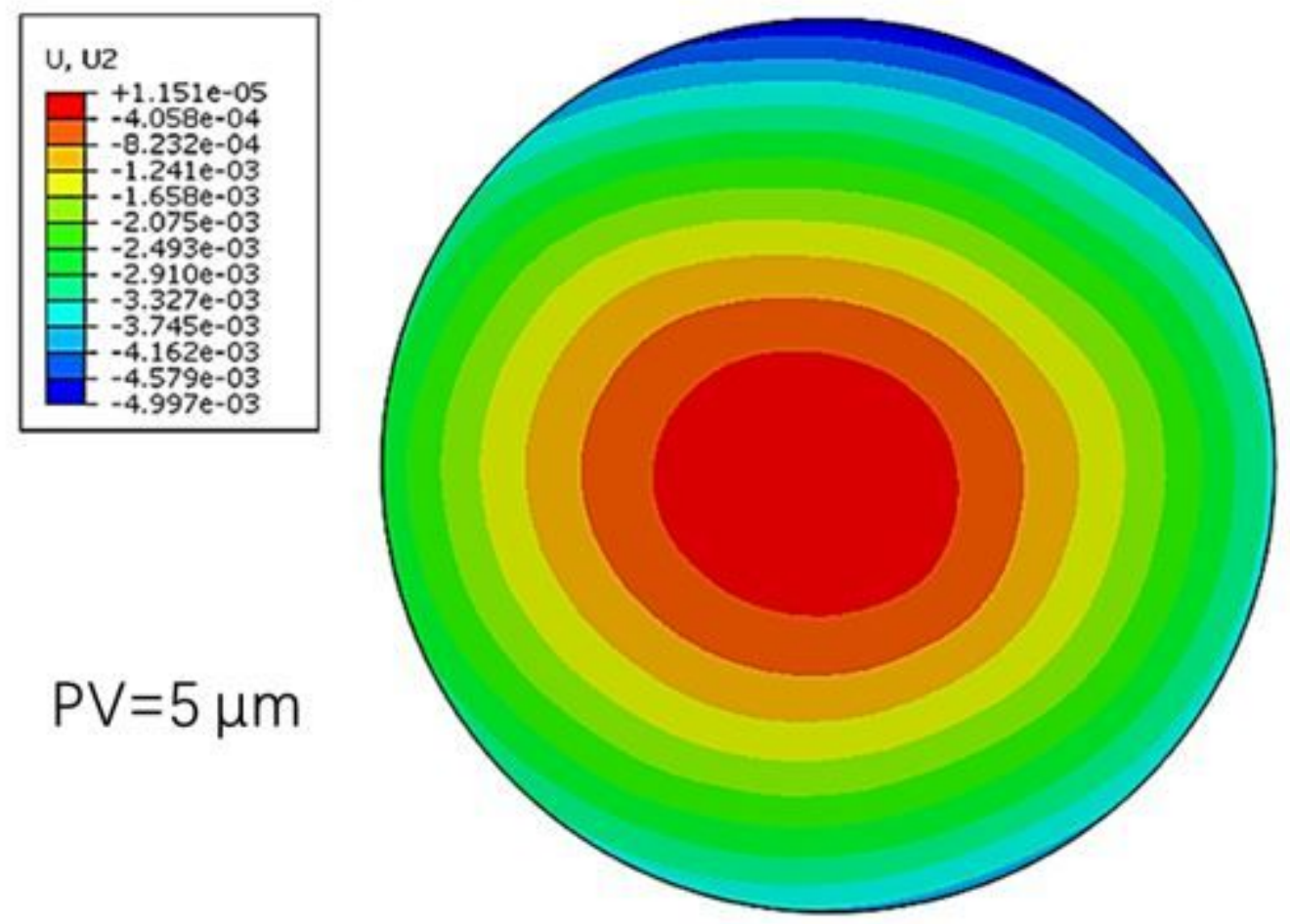

Figure 9

Deformation finite element simulation result with even material removal of upper and lower surfaces 


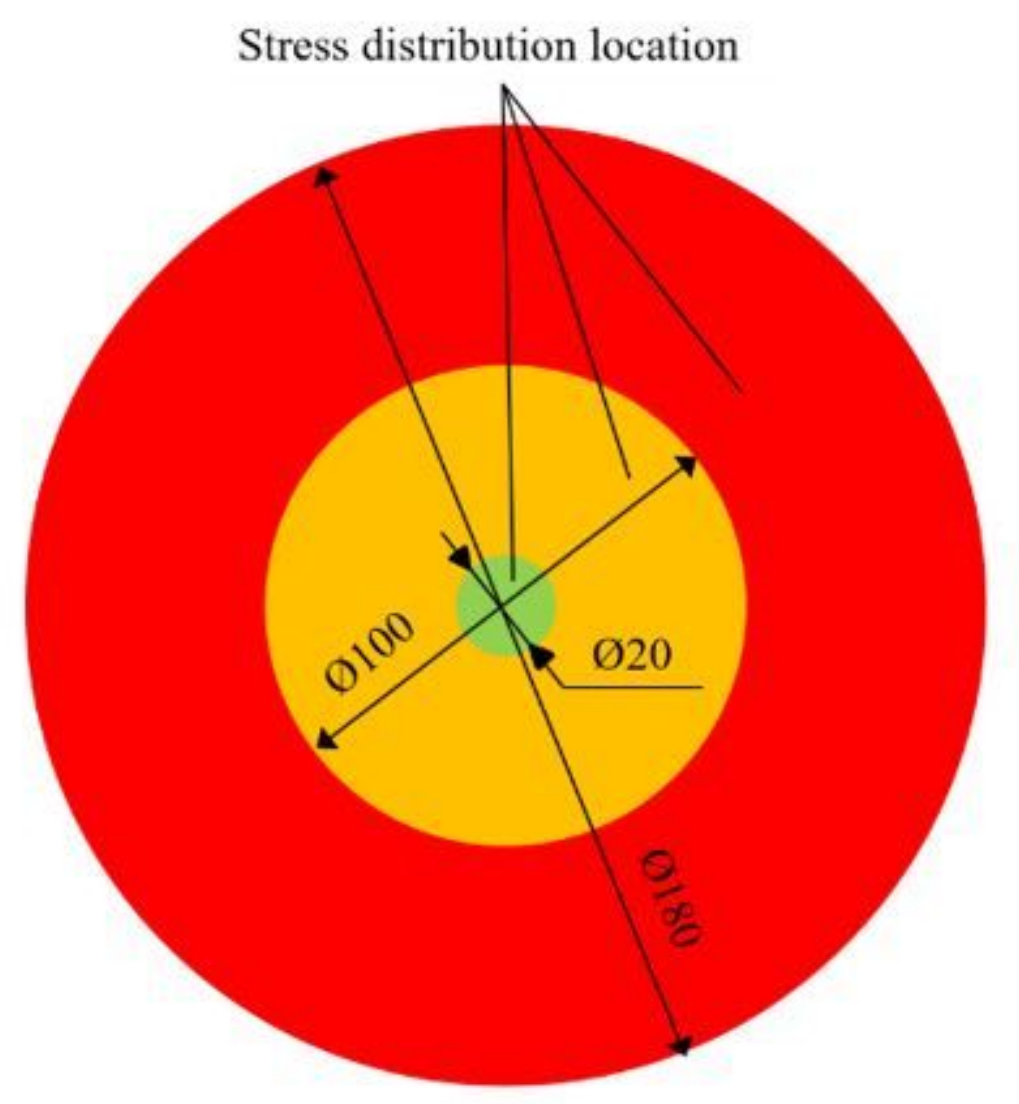

Figure 10

Stress added strategy 
(a)

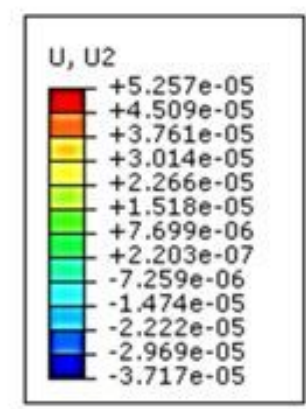

$\mathrm{PV}=0.09 \mu \mathrm{m}$

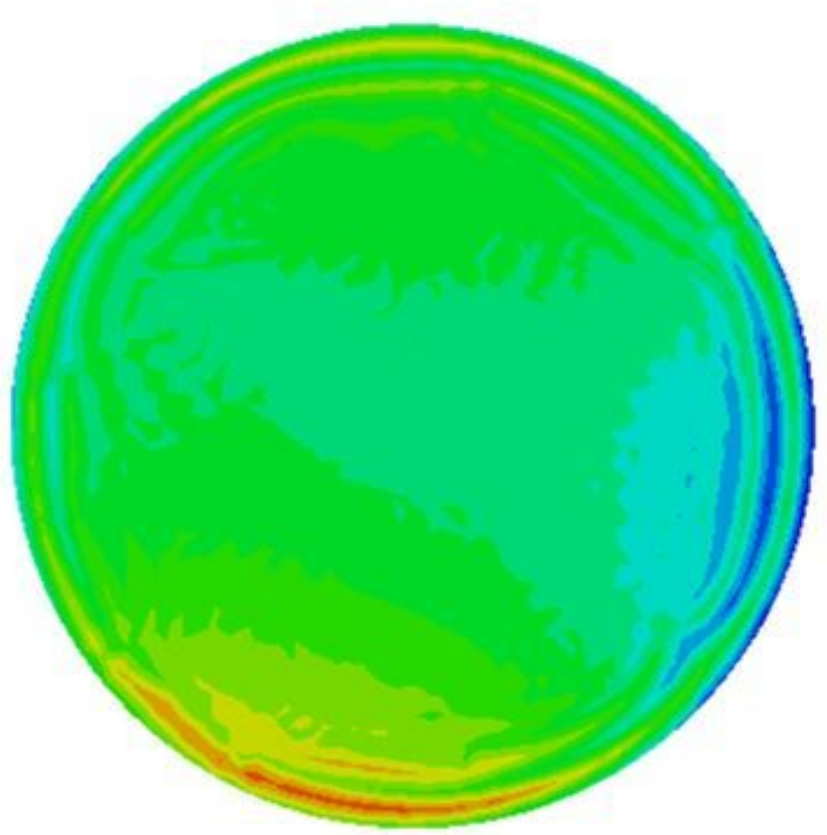

(b)

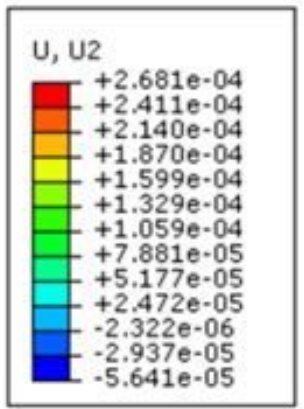

$P V=0.268 \mu \mathrm{m}$

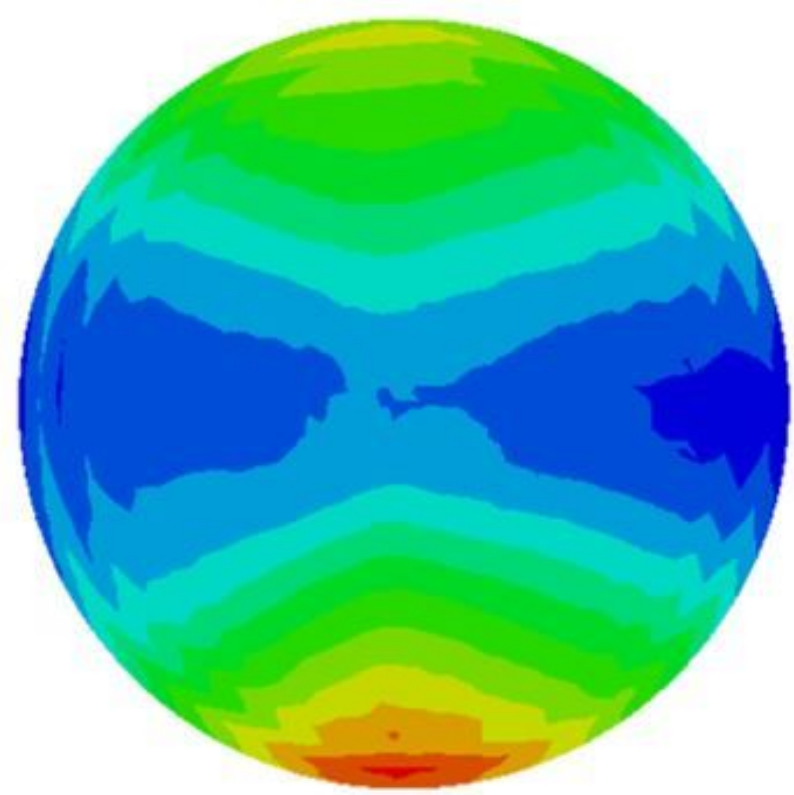

\section{Figure 11}

Simulation results of workpiece deformation caused by processing stress (a) Strategy I (b) Strategy II 


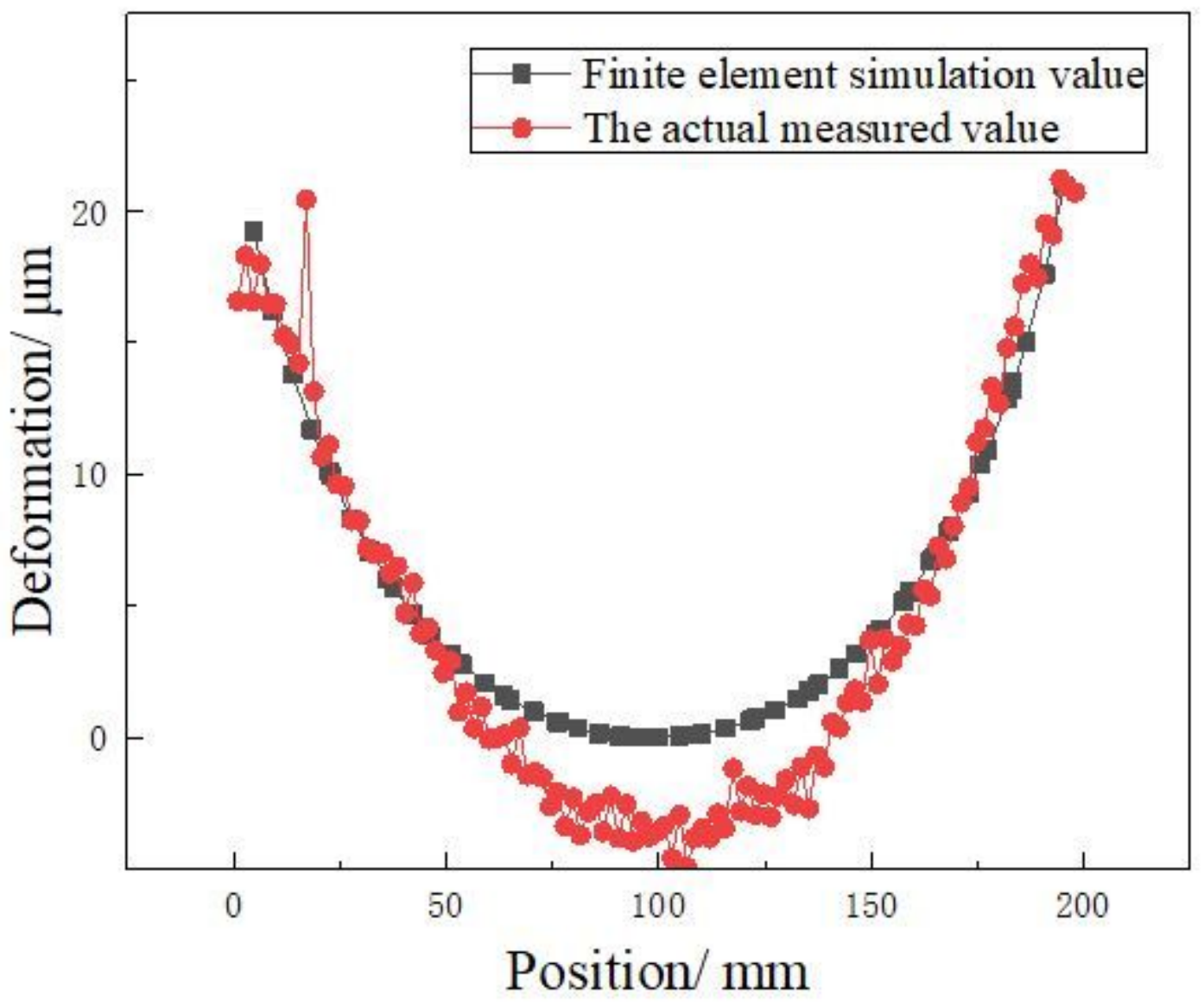

Figure 12

Measurement results of workpiece deformation with uneven material removal of upper and lower surfaces 


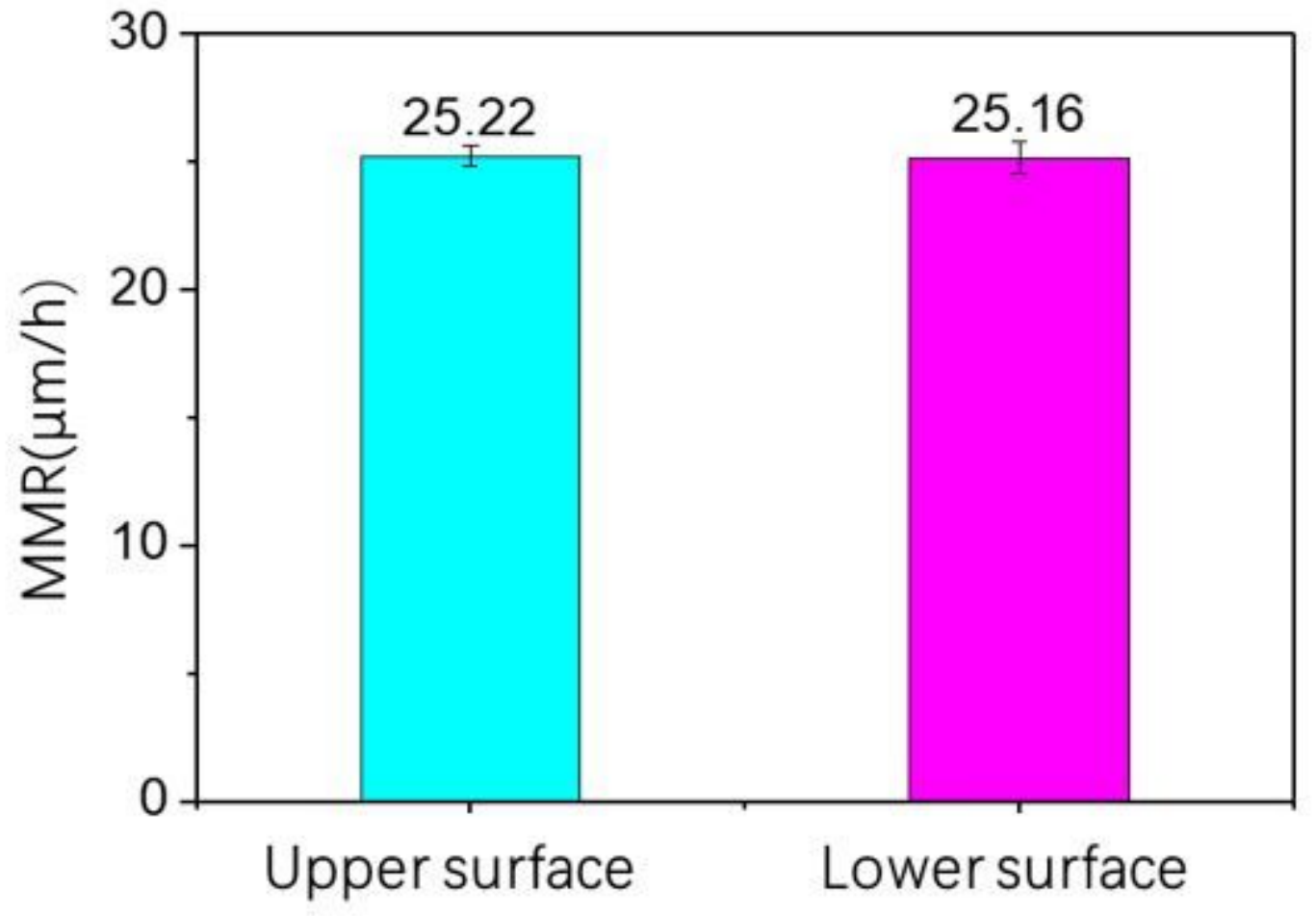

Figure 13

Materials removal rate of upper and lower surface 


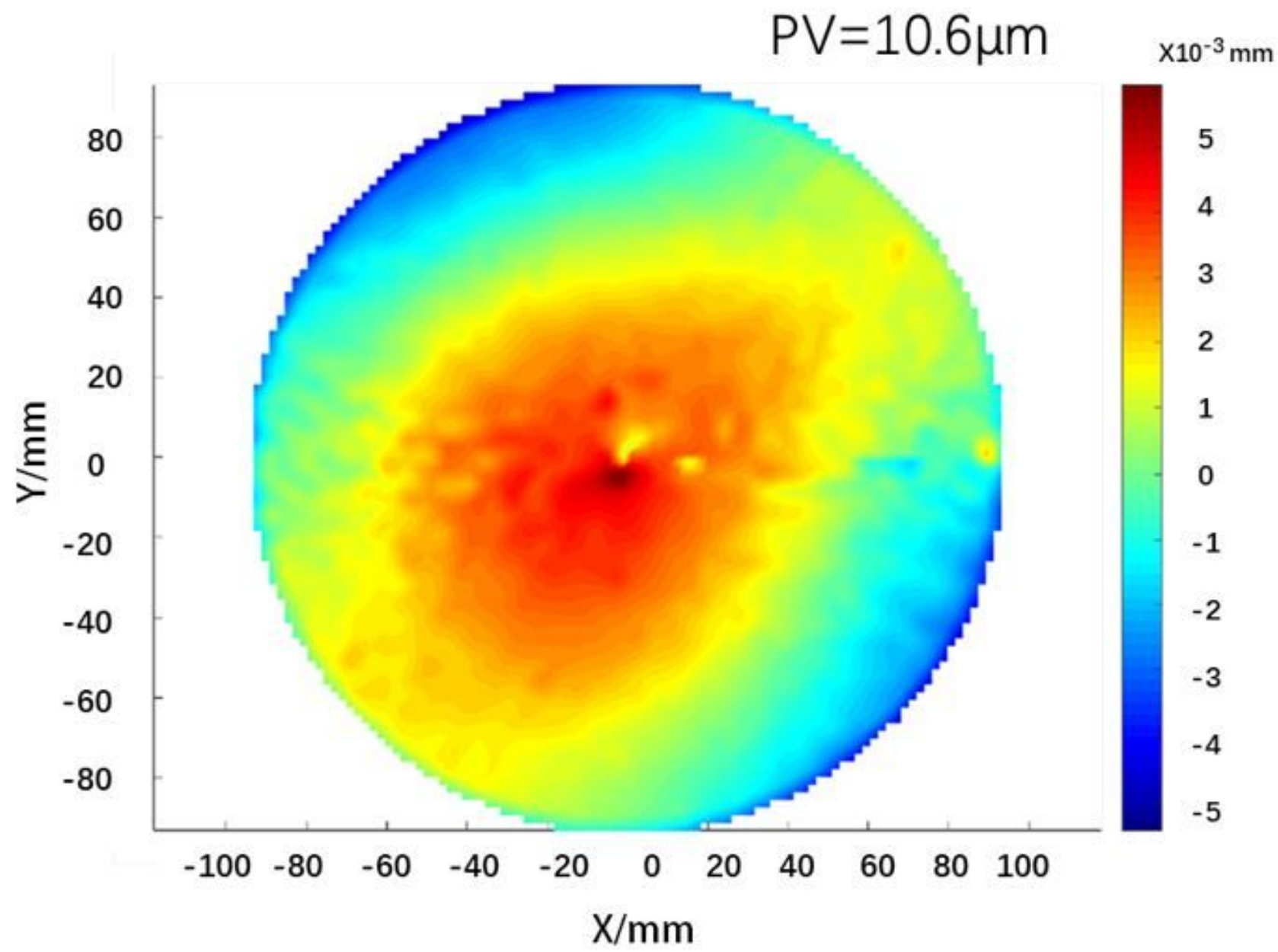

Figure 14

Measurement results of workpiece deformation with even material removal of upper and lower surfaces

\section{Supplementary Files}

This is a list of supplementary files associated with this preprint. Click to download.

- Table3.jpg 